\title{
Reliability of estimating chlorophyll a concentrations in Antarctic waters by measurement of in situ chlorophyll a fluorescence
}

\author{
O. Holm-Hansen ${ }^{1, *}$, A. F. Amos ${ }^{2}$, C. D. Hewes ${ }^{1}$ \\ ${ }^{1}$ Polar Research Program, Scripps Institution of Oceanography, University of California, San Diego, La Jolla, \\ California 92093-0202, USA
}

${ }^{2}$ University of Texas at Austin, Marine Science Institute, Port Aransas, Texas 78373, USA

\begin{abstract}
Using an extensive data set acquired in Antarctic waters in February-March of 1998, algorithms have been formulated which permit reliable estimation of chlorophyl $a$ (chl a) concentrations in the upper $100 \mathrm{~m}$ of the water column. The algorithms were derived from 105 oceanographic stations where an instrumented CTD-rosette profiling unit was deployed from the surface to $750 \mathrm{~m}$ depth. During each upcast 9 water samples were obtained at depths between 5 and $100 \mathrm{~m}$. The values for in situ chl $a$ fluorescence and solar irradiance were recorded simultaneously with collection of water at each depth. The chl a concentrations at each of the 9 depths were determined by standard laboratory procedures after extraction of the photosynthetic pigments into absolute methanol. Analysis of the data indicated that separate algorithms had to be formulated for coastal waters as contrasted to pelagic, lowbiomass, waters. Each of these 2 algorithms also required 2 equations to compensate for the inhibitory effect of solar radiation on the fluorescence yield per unit chl a. Water column data obtained during January 1998 were used to test the algorithms. The results showed that the profiles of estimated and measured chl a concentrations were similar throughout the upper $100 \mathrm{~m}$ of the water column, but that the estimated values were lower than the actual values by an average of $19 \%\left(n=528, r^{2}=0.83\right)$. It is concluded that the use of a calibrated in situ fluorometer can, with the proper algorithms, provide the investigator the detailed profile of $\mathrm{chl}$ a distribution as well as realistic estimations of the actual chl $a$ concentrations in the upper $100 \mathrm{~m}$ of the water column.
\end{abstract}

KEY WORDS: Antarctica P Phytoplankton - Chlorophyll a $\cdot$ Fluorescence $\cdot$ Photoinhibition

\section{INTRODUCTION}

Concentrations of chlorophyll a (chl a) are widely used as an indicator of phytoplankton biomass in natural waters. Although the methodology involved with the filtration, extraction, and measurement of chl a has been greatly simplified (e.g., Holm-Hansen \& Riemann 1978) as compared to the older methodology (e.g., Strickland \& Parsons 1968), the determination of chl a concentrations in natural water samples still requires considerable time and also the use of solvents (e.g., absolute methanol or acetone) which are labeled 'hazardous' and thus difficult and expensive to transport for use in field studies.

•E-mail: oholmhansen@ucsd.edu
Since the first report describing the use of in vivo $\mathrm{chl}$ a fluorescence to estimate chl a concentrations in ocean samples (Lorenzen 1966), the use of profiling in situ fluorometers to record chl a concentrations in the upper water column (Weber et al. 1986) or to detect small-scale patchiness (Astheimer \& Haardt 1984) has been incorporated as standard methodology in many ecological studies. However, the fluorescence yield per unit chl $a$ is variable and can vary by up to 1 order of magnitude, depending upon the nutritional status of the cell, variability related to species composition of the phytoplankton assemblage, and to the immediate 'light history' to which the cells have been exposed (Kiefer 1973, Falkowski \& Kiefer 1985). In spite of such variability in the fluorescence yield per unit chl $a$, the use of profiling fluorometers permits one to document 
in real time the fine structure in the profile of chl a fluorescence as related to physical, chemical, and optical conditions in the euphotic zone. The question arises, however, of how reliable such estimates of chl a can be when compared to actual chl a concentrations.

The objective in this paper is to use a large data set from Antarctic waters to describe the reliability of estimating chl a concentrations from in situ fluorescence measurements, and to determine the magnitude of deviation of such estimates from the chl a concentrations determined by conventional laboratory measurements. The algorithms developed in this study to estimate chl a concentrations from profiling fluorometer data are based on continuous profiles of chl a fluorescence from the surface to $100 \mathrm{~m}$ depth at 105 oceanographic stations during Leg II (February 3 to March 5, 1998) combined with laboratory-measured concentrations of $\mathrm{chl}$ $a$ at 8 depths at each of these 105 stations. The reliability of estimating chl a concentrations from these algorithms was then tested by comparing such estimates against the laboratorymeasured concentrations of chl $a$ at the same 105 oceanographic stations which were occupied during Leg I (January 1 to 31,1998 ).

\section{MATERIALS AND METHODS}

The studies described in this paper are a component of the United States Antarctic Marine Living Resources (AMLR) program, which has carried out oceanographic studies in the area around Elephant Island, Antarctica, for the past 9 yr. During our studies in 1998 on board the RV 'Yuzhmorgeologiya' the water-sampling grid (Fig. 1) consisted of 105 oceanographic stations, each of which was sampled 2 times during the January-March time period.

At each station, an instrumented CTD-rosette was deployed from the surface to $750 \mathrm{~m}$, or to within $10 \mathrm{~m}$ of the bottom at the shallower stations. In addition to eleven 10 I Niskin bottles equipped with teflon-covered springs, the profiling unit included the following sensors: (1) a sea-Bird CTD model SBE-9 PLUS for recording of conductivity, temperature, and depth; (2) a Sea-Tech transmissometer (25 $\mathrm{cm}$ pathlength) for recording of beam attenuation at $660 \mathrm{~nm}$; (3) a SeaTech pulsed fluorometer for estimation of chl a concentrations; and (4) a solar irradiance sensor (BSI Inc., model QCP-200L) with a cosine response for recording of attenuation of photosynthetically available radiation (PAR) with depth. Data from all sensors were acquired on both the down and up casts by a computer con-

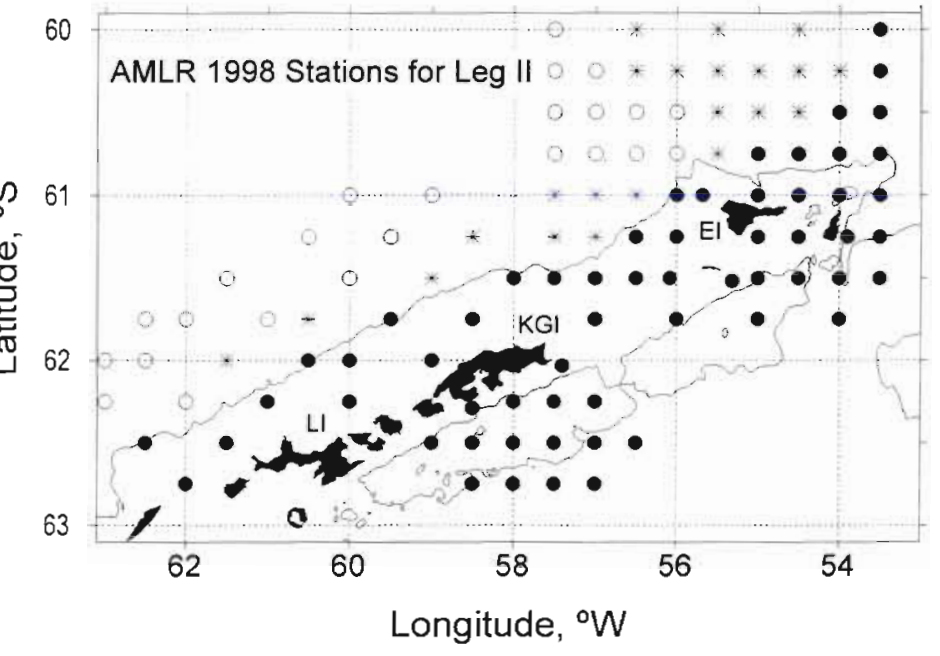

Fig. 1. Map of the sampling grid showing the location of the 105 aceanographic stations occupied during Leg II of the AMLR cruise. (O) Stations which have physical and biological characteristics for water zone $1 \mathrm{~A}$; (*) stations located in zone 1B (see 'Results' for descriptions of water zones). (•) Stations located in water zones 2 to 6 . (— $1000 \mathrm{~m}$ depth isopleth. Note that all stations in zones $1 \mathrm{~A}$ and $1 \mathrm{~B}$ are located very close to, or north, of the $1000 \mathrm{~m}$ depth contour. EI: Elephant Island; KGI: King George Island; LI: Livingston Island

nected to the Sea-Bird deck unit. All voltages from the fluorometer between 0 to $200 \mathrm{~m}$ depth were corrected by subtracting the mean voltage (approximately $0.040 \mathrm{~V}$ ) recorded at $750 \mathrm{~m}$, where chl a concentrations are nearly always equal to or less than $0.01 \mathrm{mg} \mathrm{m}^{-3}$. Incident solar radiation (photosynthetically active radiation, PAR) was also monitored and recorded continuously with a $2-\pi$ sensor (BSI Inc., model QSR-240) which was mounted in a shade-free location on the ship's superstructure.

Water samples were obtained on the upcasts when the winch was stopped at standard depths of 750,200 , $100,75,50,40,30,20,15,10$, and $5 \mathrm{~m}$. At the same time that the Niskin bottles were closed at depth, the values from all sensors on the rosette were also recorded by the shipboard computer. For determination of chl a concentrations in the water samples, $100 \mathrm{ml}$ aliquots were filtered at a pressure differential of $<150 \mathrm{~mm} \mathrm{Hg}$ through a $25 \mathrm{~mm}$ glass fiber filter (Whatman GF/F), which was then placed in $10 \mathrm{ml}$ of absolute methanol (Holm-Hansen \& Riemann 1978). After extraction in the dark for at least $2 \mathrm{~h}$, chl a concentrations were determined by measurement of chl a fluorescence (Holm-Hansen et al. 1965) in a Turner Designs fluorometer (model 700) which had been calibrated against purified chl a (Sigma C-6144) and the instrument response checked daily with a coproporphyrin standard (Sigma C-4529) as well as with a solid state fluorescence standard (Turner Designs No. 7000-994). 


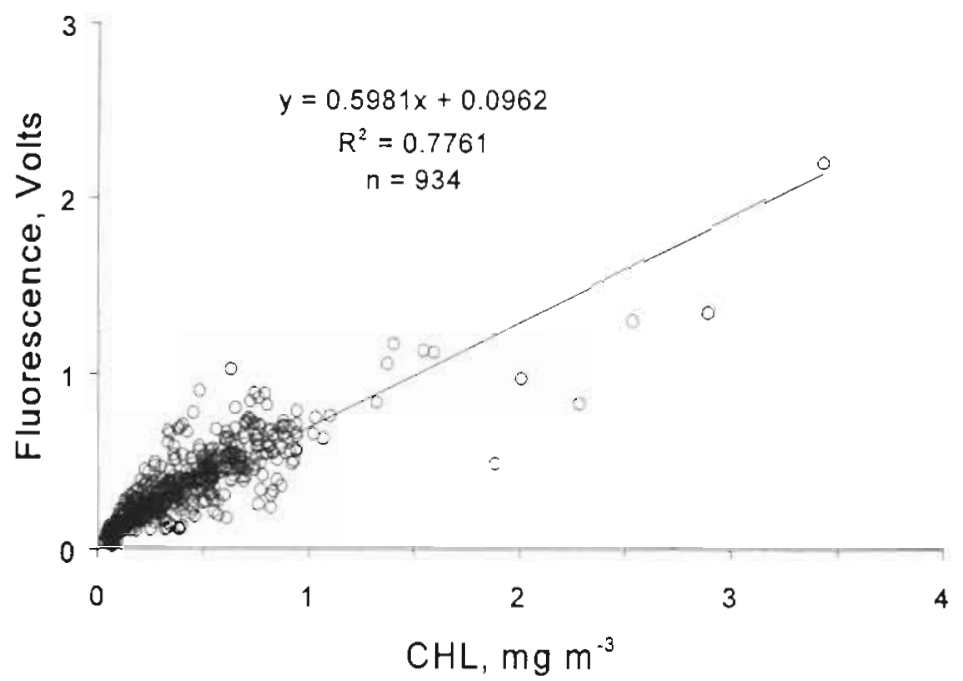

Fig. 2. Relationship between chl a fluorescence measured with an in situ fluorometer and laboratory measured chl a concentrations in water samples obtained from 9 depths between 5 to $100 \mathrm{~m}$ at 105 oceanographic stations in Antarctic waters, together with the linear regression line for the data. See 'Methods' for details

During Leg I (January 1 to 31,1998 ) chl a concentrations were routinely determined only at depths of 5,10 , 30 , and $50 \mathrm{~m}$ (and less often at the other 5 depths) due to a shortage of absolute methanol. During Leg II (February 3 to March 5, 1998) chl a concentrations were determined at all 9 depths between 5 and $100 \mathrm{~m}$. Data from Leg II were thus used in developing the algorithms to estimate chl a concentrations from in vivo chl a fluorescence values. The term $F_{N}$ (fluorescence normalized to chl a concentration) will be used to express the value of the ratio of in situ fluorescence at depth divided by the measured chl a concentration as determined after extraction in methanol.

\section{RESULTS}

Data in Fig. 2 show that there is a good correlation $\left(r^{2}=0.78\right)$ between the voltage of the profiling fluorometer recorded at the same depths from which the 9 water samples were obtained during Leg II and the extracted chl a values at those depths for all 105 oceanographic stations. There was, however, a fair amount of scatter in the data. In order to refine the algorithm to calculate chl a concentrations from fluorometer voltages, the data were further analyzed in regard to inhibition of fluorescence resulting from solar radiation and also variations in fluorescence yield in the various water masses (see Holm-Hansen et al. 1997) occurring in the sampling area.

In order to see if in vivo fluorescence values were affected by the presence or absence of solar radiation, data from Fig. 2 were broken down into 2 groups - values obtained at stations occupied during the night (21:00 to 05:00 h local time) and those stations occupied during daytime $(07: 00$ to $17: 00 \mathrm{~h})$. Data obtained during night time (Fig. 3A) show more fluorescence per unit chl a (slope of $0.80, \mathrm{r}^{2}=0.88$ ) than data obtained during the daytime (Fig. 3B), which show a slope of 0.52 with $r^{2}=0.81$ (ANOVA, $p<0.001$ ). It is thus apparent that solar radiation does decrease the
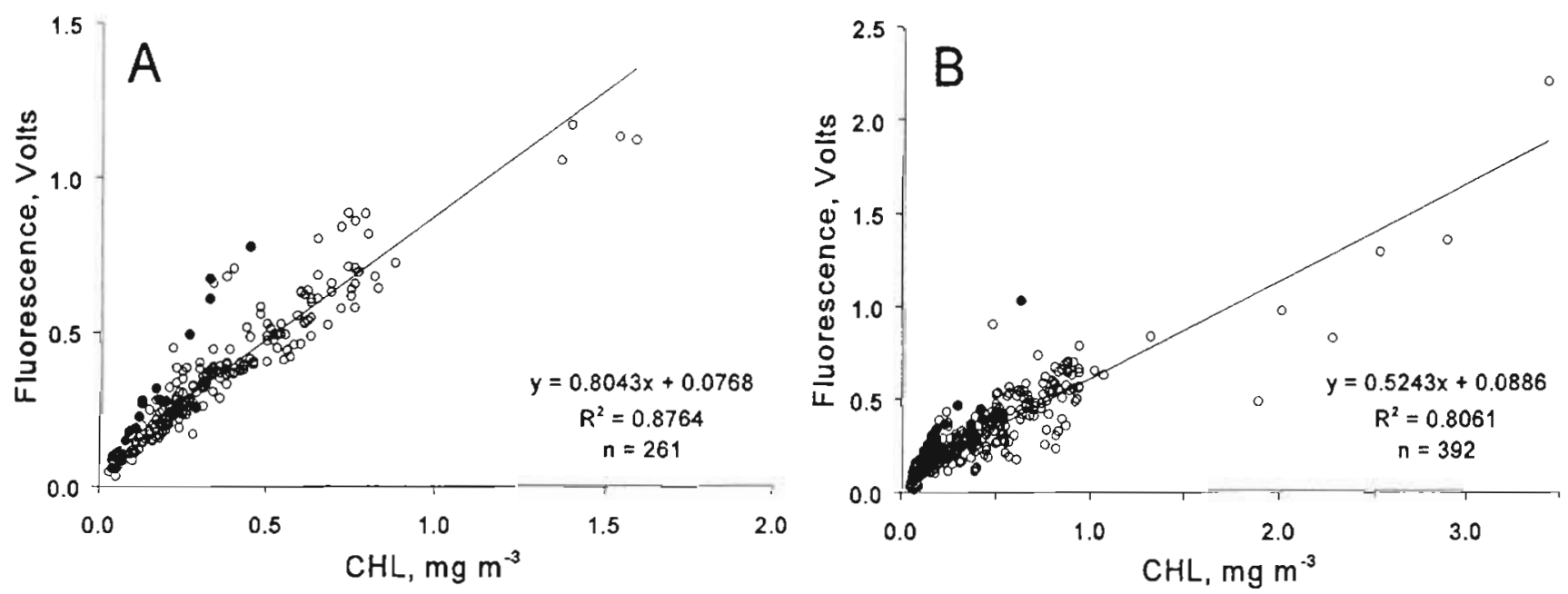

Fig. 3. Effect of solar radiation on fluorescence yield per unit chl a at 9 depths between 5 to $100 \mathrm{~m}$ at 105 oceanographic stations in Antarctic waters. (A) Data from all stations occupied between 21:00 and 05:00 h, when there was very little or no solar radiation. (B) Data from all stations occupied between $07: 00$ and $17: 00 \mathrm{~h}$, when incident solar radiation generally exceeded $50 \mu \mathrm{mol} \mathrm{m}^{-2} \mathrm{~s}^{-1}(\bullet)$ Data from stations located in water zone $1 A_{;}(0)$ data from stations in water zones $1 B$ and 2 to 6 (see Fig. 1 for location of water zones) 
amount of in vivo fluorescence per unit chl $a$ and that this inhibition of fluorescence must be taken into account when estimating chl a concentrations from in situ fluorescence data.

The magnitude of inhibition of fluorescence by solar radiation in the upper water column will be a function of the irradiance at that depth, so it is necessary to analyze $F_{\mathrm{N}}$ as a function of irradiance to which phytoplankton were exposed at the time of sampling. When all the values for $F_{\mathrm{N}}$ obtained during Leg II were plotted against solar irradiance as measured at the same depth and at the same time as the in vivo fluorescence was measured, there was considerable scatter in the data, particularly in the values obtained in low-light or dark conditions (Fig. 4). The cause for the large variability in fluorescence per unit chl $a$ at night appears to be related to varying physiological characteristics of phytoplankton in zone 1 waters as compared to phytoplankton in the waters of zones 2 to 6 (see 'Discussion').

Preliminary analysis of our fluorescence data indicated that values of $F_{\mathrm{N}}$ were often highest for stations located in the northerly portion of our sampling grid. In order to understand why there is such variability in the values of $F_{\mathrm{N}}$, particularly under low-light or in darkness, it is necessary to examine the environmental conditions for phyioplankton within the AMLR study area. Previous studies have shown that there are 6 water masses in the AMLR sampling grid, which can be differentiated on the basis of physical characteristics (Holm-Hansen et al. 1997). The water mass that is most easily distinguished from the other water masses is zone 1 (Drake Passage water), which is characterized by: (1) residual Antarctic Surface Winter Water (AASW) with a temperature minimum $<0^{\circ} \mathrm{C}$ at approximately $80 \mathrm{~m}$ depth; (2) low chl a concentrations (gener-

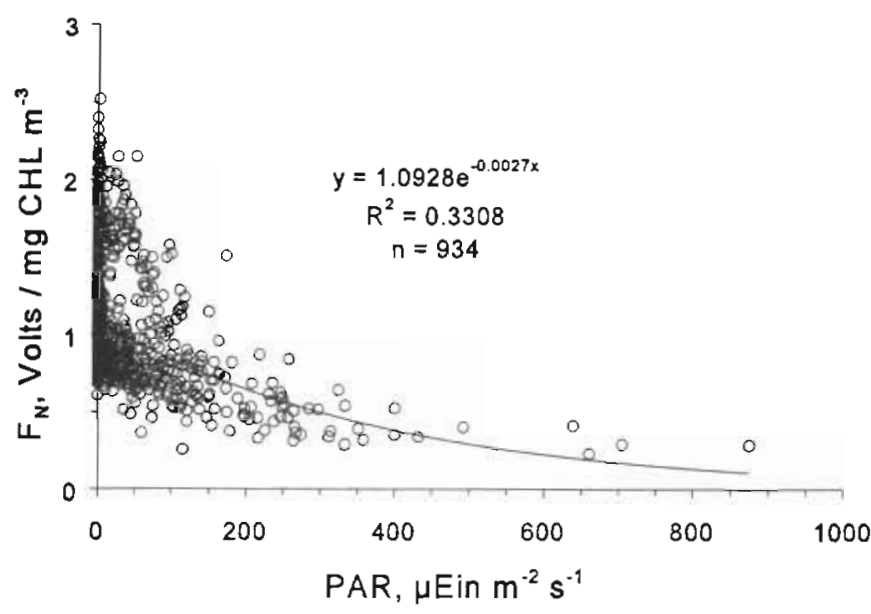

Fig. 4. Inhibitory effect of solar radiation on fluorescence per unit chl $a$ in natural phytoplankton assemblages in the upper water column ( 5 to $100 \mathrm{~m}$ ) in Antarctic waters. See 'Methods' for details
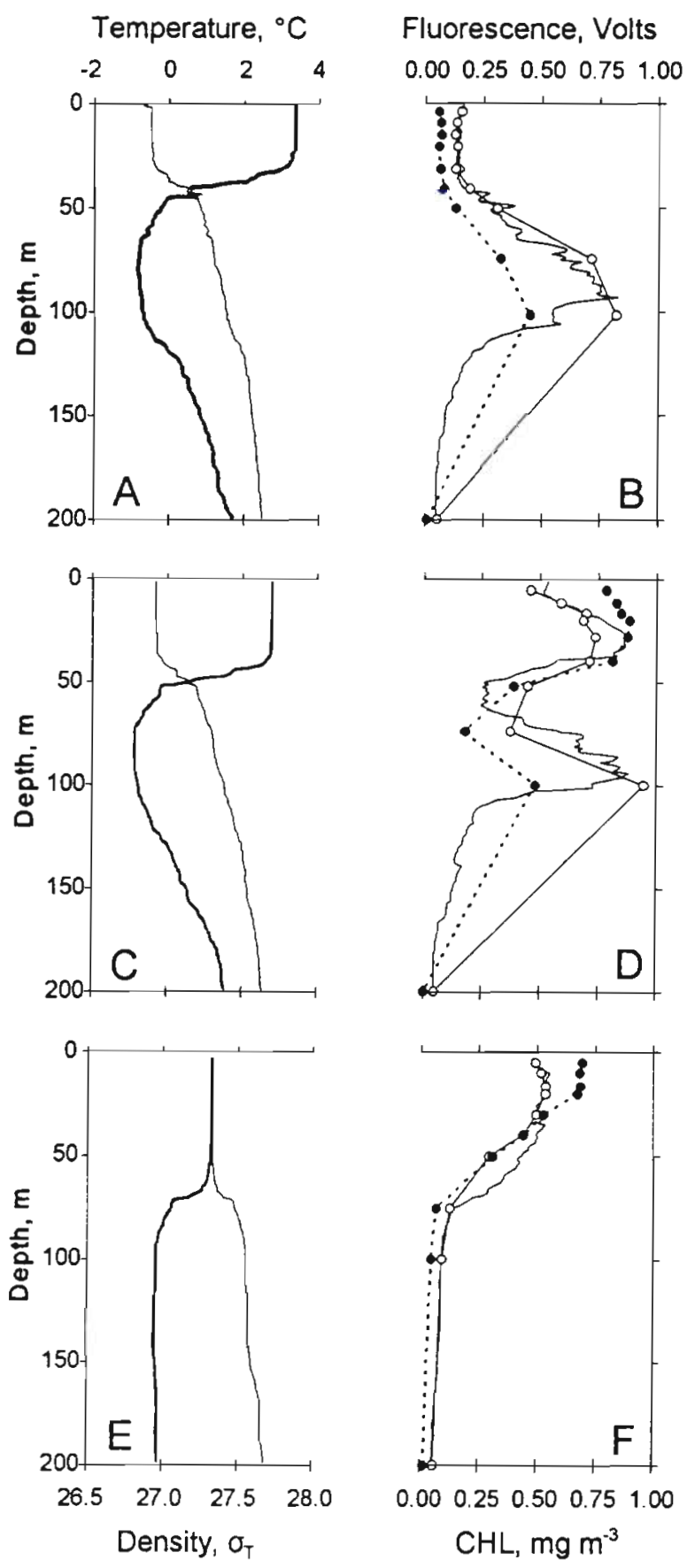

Fig. 5. Temperature (-), water density $(-)$ and chl $a$ concentrations in the upper $200 \mathrm{~m}$ of the water column at 3 representative stations in the AMLR sampling grid. $\mathrm{Chl} a$ concentrations are indicated by the in vivo fluorescence trace during the downcast (- - ), by measured fluorometer voltages at the sampling depths during the upcast $(0)$, and by laboratory-measured concentrations in the water samples obtained during the upcast $(\bullet)$. (A, B) Stn D110, representative of water zone $1 \mathrm{~A}$. (C, D) Stn D104, representative of water zone 1B. $(E, F) S t n$ D038, representative of water zones 2 to 6 . The solar irradiances at $5 \mathrm{~m}$ depth at the time of sampling for the above 3 stations were 0,333 , and $56 \mathrm{umol} \mathrm{m}^{-2} \mathrm{~s}^{-1}$, respectively 


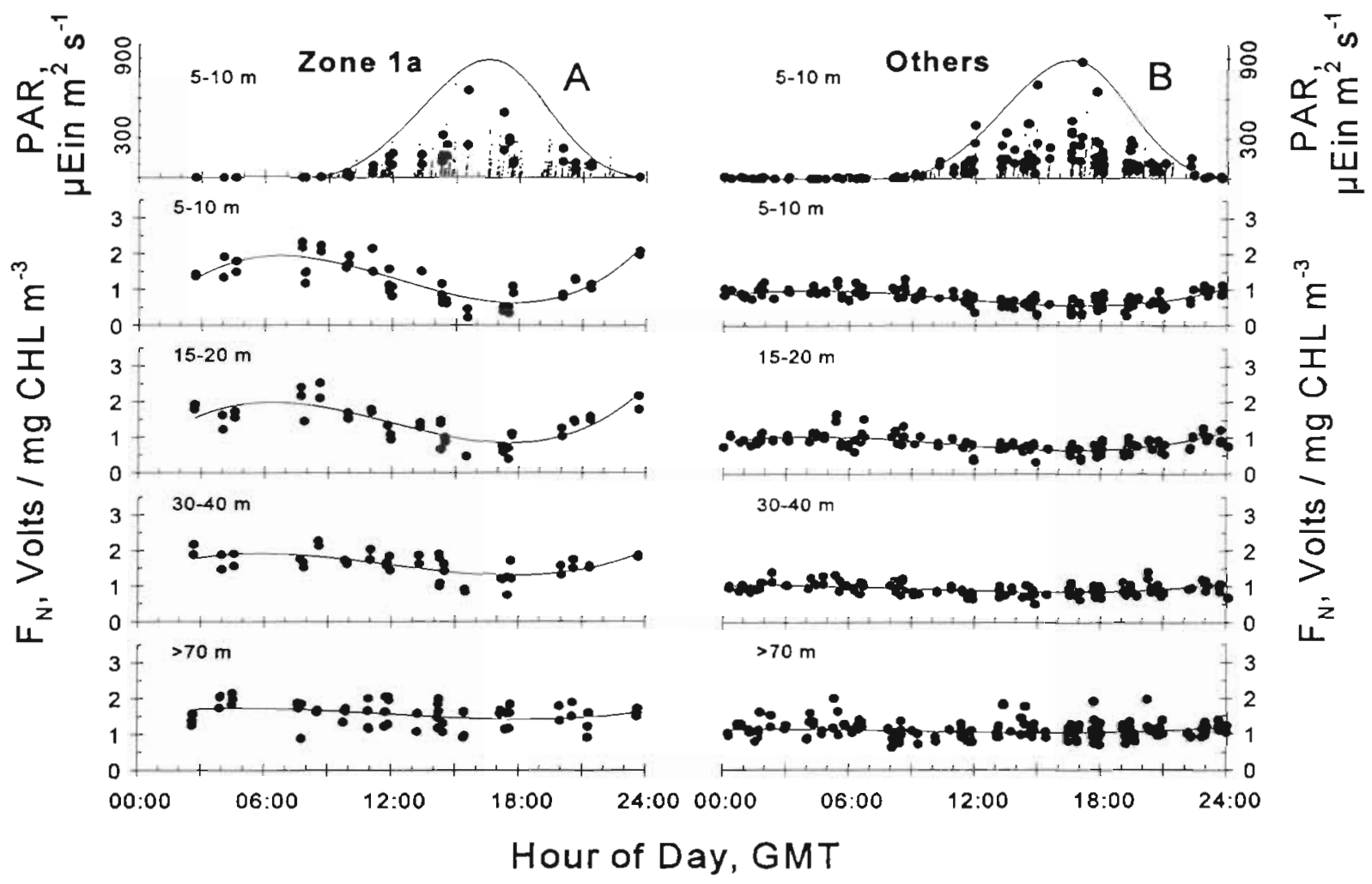

Fig. 6. Values of $F_{\mathrm{N}}$ within 4 depth zones $(5-10,15-20,30-40$, and $70-100 \mathrm{~m})$ as related to the time of sampling during each $24 \mathrm{~h}$ period. Values on the abscissa are Greenwich Mean Time (GMT), which is $3 \mathrm{~h}$ ahead of local time during the field studies. (A) Data from stations in water zone $1 \mathrm{~A}$. (B) All data from stations in water zones $1 \mathrm{~B}$ and zones 2 to 6 . The uppermost panels in (A) and (B) show the daily periodicity in incident solar radiation experienced by samples at 5-10 $\mathrm{m}$ for all stations during Leg II: (•) stations within the designated water zone $(s)_{i}(\cdot)$ data from all other stations; $(-$ ) normal Gaussian distribution of solar radiation (PAR) throughout each $24 \mathrm{~h}$ period. The continuous lines in the panels for the 4 depth zones represent the best-fit thirdorder polynomial equations for the data within each depth zone

ally $<0.1 \mathrm{mg} \mathrm{chl} a \mathrm{~m}^{-3}$ ) in the upper 30 to $40 \mathrm{~m}$ of the water column; and (3) a deep chl a maximum (0.3 to $0.8 \mathrm{mg} \mathrm{chl} \mathrm{a} \mathrm{m}^{-3}$ ) at depths close to $80 \mathrm{~m}$. Water masses 2 through 6 consist of waters originating in the Bellingshausen Sea, Bransfield Strait, the Weddell Sea, or mixtures of these waters with Drake Passage waters. Examination of temperature-salinity diagrams, as well as biological and nutrient data for stations in zone 1, however, indicates that stations in this zone can be divided into 2 subgroups (Holm-Hansen et al. 1997): zone 1A stations, which show the characteristics listed above, and zone $1 \mathrm{~B}$ stations, which indicate that there has been some mixing of Drake Passage waters with contiguous water masses, as elevated chl a concentrations and relatively high concentrations of silicic acid are found in surface waters ( 0 to $30 \mathrm{~m}$ ) at these stations. Examples of the differences in physical and biological characteristics of the upper water column at stations located in zones $1 \mathrm{~A}, 1 \mathrm{~B}$, or 2 to 6 are shown in Fig. 5; stations located in these water zones are indicated in Fig. 1. The species composition of the phytoplankton in all 6 water zones include many species of diatoms, di- noflagellates, cryptophytes, and small $(<5.0 \mu \mathrm{m})$ flagellates (Villafañe et al. 1995). It is thus unlikely that the large differences in fluorescence per unit chl a under low-light conditions for phytoplankton in water zone 1 , as compared to specific fluorescence data for phytoplankton in water zones 2 to 6 , are related to the phylogenetic composition of the phytoplankton community.

Preliminary examination of our data showed that the influence of solar radiation on $F_{N}$ values for stations in zone $1 \mathrm{~B}$ were fairly close to the values of $F_{\mathrm{N}}$ in zones 2 to 6 , with the exception of data from depths of 50 to $80 \mathrm{~m}$, where $F_{\mathrm{N}}$ values were closer to values in zone 1A. Samples from this depth interval $(50$ to $80 \mathrm{~m}$ ) lie within the temperature-minimum layer of AASW, which is characteristic of all zone 1 stations. However, as there were relatively few data points represented by samples in this 50 to $80 \mathrm{~m}$ depth range, all sample data from zone $1 \mathrm{~B}$ have been incorporated with the sample data from zones 2 to 6 . Although photoinhibition of chl a fluorescence is commonly believed to be apparent only in the upper 5 to $10 \mathrm{~m}$ of the water column, the data shown in Fig. 6 show that solar inhibition of $F_{\mathrm{N}}$ 
values can be seen down to depths of at least 30 to $40 \mathrm{~m}$. This effect is more pronounced in zone $1 \mathrm{~A}$ waters (Fig. 6A) than in the other zones (Fig. 6B). As the mean euphotic zone depth in the AMLR sampling grid is close to $90 \mathrm{~m}$ (Helbling et al. 1995), irradiances at 30 to $40 \mathrm{~m}$ depth would be in the range of approximately $15 \%$ of solar PAR incident upon the sea surface.

In order to develop an algorithm to estimate chl a concentrations from fluorometer voltages it is necessary to determine if there is a threshold value for the inhibition of chl a fluorescence by solar radiation. The data in Fig. 6 clearly indicate that there is increasing inhibition of chl a fluorescence with increasing solar radiation, but the method of plotting does not allow one to see if there is a threshold of radiation below which the values of $F_{\mathrm{N}}$ remain fairly constant. The data shown in Fig. 6 have therefore been replotted with solar irradiance on a log scale. It is seen from the resulting plots (Fig. 7) that there is an apparent threshold value for photoinhibition of fluorescence at approximately $40 \mu \mathrm{mol} \mathrm{m} \mathrm{m}^{-2} \mathrm{~s}^{-1}$. This threshold is most noticeable for samples in zone 1A (Fig. 7A) and least noticeable for samples in the other water zones (Fig. 7B). The data also show that the values of $F_{\mathrm{N}}$ at stations located in zone $1 \mathrm{~A}$ (Fig. $7 \mathrm{~A}$ ) are significantly higher at irradiances of less than $40 \mu \mathrm{mol} \mathrm{m} \mathrm{m}^{-2} \mathrm{~s}^{-1}\left(F_{\mathrm{N}}\right.$ values of approximately 1.70 ) than the values of $F_{\mathrm{N}}$ for stations located in the other zones, where the values are approximately . 1.0 (Fig. 7B). At irradiances $>40 \mu \mathrm{mol} \mathrm{m}^{-2} \mathrm{~s}^{-1}$, $F_{\mathrm{N}}$ values for samples in all water zones decreased markedly with increasing irradiance as shown by the data and equations in Fig. 7A,B. The algorithms to be used for estimation of chl a concentrations from in situ fluorescence data are thus as follows:

\section{Stations in water zone $1 \mathrm{~A}$}

chl $a\left(\mathrm{mg} \mathrm{m}^{-3}\right)=$ Volts $/[0.013 \log (\mathrm{PAR}+1)+1.68]$, when PAR $<40 \mu \mathrm{mol} \mathrm{m} \mathrm{m}^{-2} \mathrm{~s}^{-1}$

chl a $\left(\mathrm{mg} \mathrm{m}^{-3}\right)=$ Volts $/[-1.32 \log (\mathrm{PAR}+1)+3.77]$, when PAR $>40 \mu \mathrm{mol} \mathrm{m} \mathrm{m}^{-2} \mathrm{~s}^{-1}$

\section{Stations in all other water zones}

chl a $\left(\mathrm{mg} \mathrm{m}^{-3}\right)=$ Volts $/[-0.156 \log (\mathrm{PAR}+1)+1.08]$, when PAR $<40 \mu \mathrm{mol} \mathrm{m} \mathrm{m}^{-2} \mathrm{~s}^{-1}$

chl a $\left(\mathrm{mg} \mathrm{m}^{-3}\right)=$ Volts $/[-0.412 \log (\mathrm{PAR}+1)+1.49]$, when PAR > $40 \mu \mathrm{mol} \mathrm{m} \mathrm{m}^{-2} \mathrm{~s}^{-1}$

These 105 stations were occupied during Leg I of the 1998 AMLR field season, but chl a concentrations were

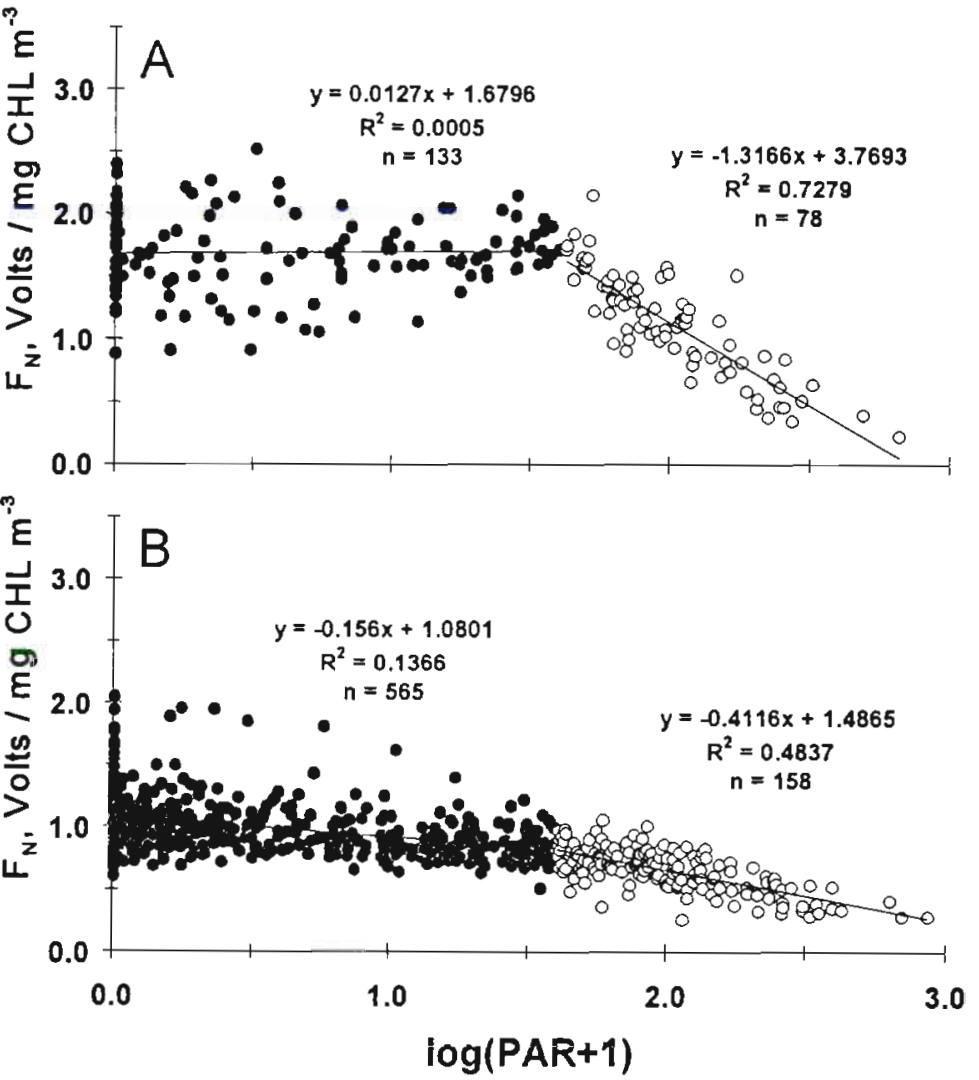

Fig. 7. Inhibitory effect of solar radiation on the specific fluorescence yield $\left(F_{N}\right)$ of phytoplankton as influenced by the water zone in which the station is located. Values for in situ fluorescence and for solar radiation are the values measured at depth at the time of obtaining the water sample was obtained. Values for solar irradiance are expressed as $\log (\mathrm{PAR}+1)$ in order to eliminate negative values on the abscissa. (A) All data from zone $1 \mathrm{~A}$ stations; $(B)$ all data from water zones $1 B$ and 2 to 6 . Sampling depths were between 5 to $100 \mathrm{~m}$. (॰) PAR values of $<40 \mu \mathrm{mol} \mathrm{m} \mathrm{m}^{-2} \mathrm{~s}^{-1}$, (o) PAR values of $>40 \mu \mathrm{mol} \mathrm{m} \mathrm{m}^{-2} \mathrm{~s}^{-1}$

measured routinely at only 4 depths $(5,10,30$, and $50 \mathrm{~m})$ per station instead of at all 9 depths as on leg II. Samples from other depths were obtained at selected stations in conjunction with primary productivity studies. On the basis of the temperature and fluorometer profiles recorded at each station during Leg I, all 105 stations were divided into zone $1 \mathrm{~A}$ stations (total of 26 stations), with all the other stations in water zones $1 B$ and 2 to 6 being grouped together (total of 79 stations). The chl a concentrations for all sampled depths during Leg I were then calculated from the fluorometer and light meter data by use of the 4 equations given above, and compared with the actual chl a concentrations as determined in the laboratory. The results (Fig. 8) show the profiles of estimated chl a concentrations with depth are very similar to the profiles of measured values, but that the estimated concentrations are slightly lower than the measured values at all 9 sampling depths. Since the variability for the estimated versus the actual chl a concen- 
trations overlap considerably at all sampled depths, there is no great error for estimating chl a concentrations from fluorescence, either in zone 1A samples (Fig. 8A) or in samples from the other water zones (Fig. 8B), if used to describe the general distribution of phytoplankton with depth in the water column. Paired $t$-tests of estimated versus extracted chl a values for each depth in both zones $1 \mathrm{~A}$ and $1 \mathrm{~B}$ to 6 found differences $(\mathrm{p}<0.05)$ in only $50 \%$ of the 18 comparisons. When all the data from the 105 stations are compared, the in vivo fluorescence method underestimated extracted chl a values by $19 \%$ ( $\left.\mathrm{n}=528, r^{2}=0.831\right)$.

\section{DISCUSSION}

As was noted in the 'Results', preliminary analysis of our data from the entire AMLR sampling grid indicated $F_{\mathrm{N}}$ values in zone $1 \mathrm{~A}$ waters were significantly higher than $F_{N}$ values in the other water zones encountered in our study area isee Holm-Hansen et al. 1997, for description of these water zones). This necessitated the formulation of separate algorithms for estimation of chl a concentrations from in situ fluorescence data. It should be noted that stations in zone $1 \mathrm{~A}$ waters are easily differentiated from stations in the other water zones in the AMLR study area by the low chl a concentrations in surface waters, a deep chl a maximum between 60 to $80 \mathrm{~m}$ depth, and the presence of a temperature minimum close to $80 \mathrm{~m}$. Previous studies have furnished strong support for the hypothesis that phytoplankton biomass in zone $1 \mathrm{~A}$ waters is limited by $\mathrm{Fe}$ availability (Helbling et al. 1991), which provides a possible physiological basis for the increased fluorescence per unit chl a noted in these waters.

When our 4 algorithms were applied to profiled fluorescence data from Leg I of the AMLR cruise, the closeness of the estimated chl a concentrations with the measured chl a values (Fig. 8) suggests that the use of a profiling fluorometer can provide a reliable continuous profile of chl a concentrations with depth. This will be valuable when interpreting the distribution and biomass of phytoplankton in relation to physical, optical, and chemical parameters in the upper few hundred meters of the water colunm. However, the algorithms presented should be considered as first approximations, and the following precautions must be taken into consideration:
(1) Chl a concentrations measured in the AMLR survey area during 1998 were generally lower than the $9 \mathrm{yr}$ mean of the AMLR program. The linear relationships described by our algorithms have not been adequately tested against concentrations often found for bloom conditions where chl a concentrations exceed $2 \mathrm{mg} \mathrm{m}^{-3}$

(2) The highest irradiance at $5 \mathrm{~m}$ depth in our data set used to develop the algorithms was $870 \mu \mathrm{mol} \mathrm{m} \mathrm{m}^{-2}$ $\mathrm{s}^{-1}$ (Fig. 7). On sunny days closer to the summer solstice, solar irradiance at $5 \mathrm{~m}$ depth may well exceed our highest measured value. If our algorithm (Eq. 2) were applied to such very high-irradiance days, the predicted $F_{\mathrm{N}}$ values would approach a value of zero, which is unrealistic. It is apparent that the algorithm for use in zone $1 \mathrm{~A}$ waters (and perhaps also the algorithm in Eq. 4) under conditions of high solar irradiances will have to be modified slightly to incorporate realistic values of $F_{N}$ under such conditions. This high irradiance portion of the algorithms would either incorporate a decreased slope or a constant (as a plateaued minimum) after some determined irradiance value.

(3) It should be noted that all the data discussed here were for Antarctic waters, which are characterized by low temperatures and high concentrations of the essential macro-elements. Our data show, however, that even in Antarctic waters there are substantial differences in fluorescence yields per unit chl a between

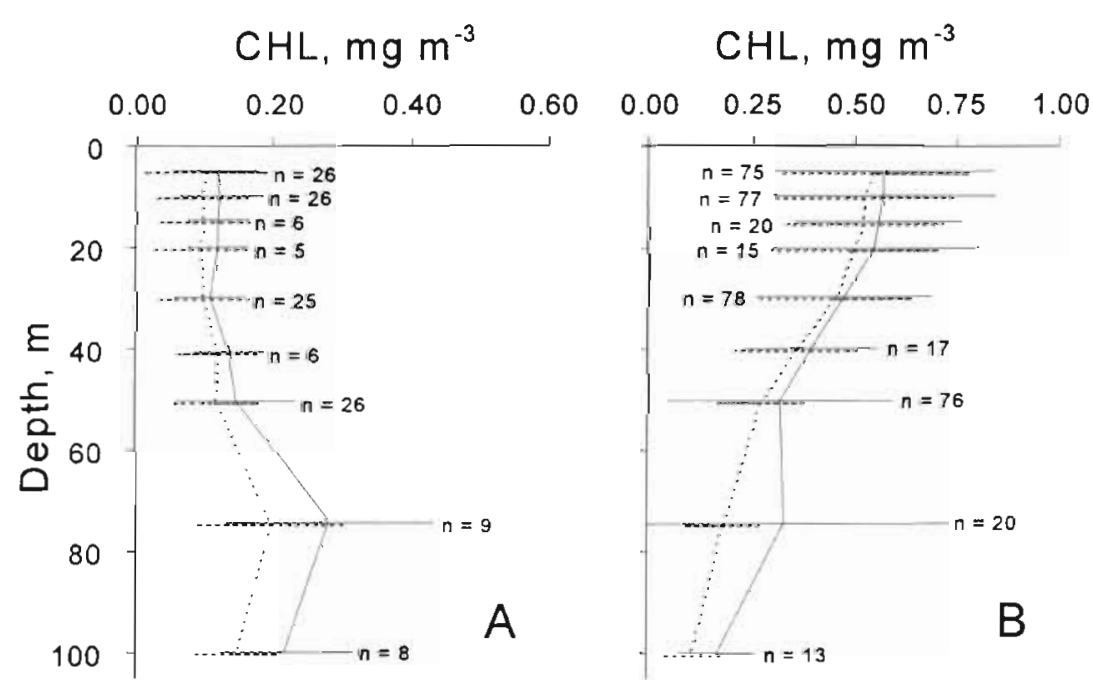

Fig. 8. Comparison of chl a concentrations as estimated by application of the algorithms with the measured $\mathrm{chl}$ a concentrations at depths between 5 and $100 \mathrm{~m}$ at 105 oceanographic stations during Leg I of the AMLR field program in January 1998. (A) Data from stations in water zone $1 A_{i}(B)$ data from stations in all other water zones. Solid line: mean chl a concentrations at the 9 samples depths ( $\mathrm{n}=$ no. of samples at that depth), with \pm SD being indicated by the horizontal lines. Dashed line: chl a concentrations at the same depths as estimated from fluorometer-voltage data and application of the 4 algorithms described in the text (Eqs. 1 to 4). Dashed horizontal lines: \pm SD of the estimated chl a concentrations at each depth 
oceanic areas where it is believed cells are stressed by Fe limitation and those coastal regions which have high $\mathrm{Fe}$ concentrations. It is likely that our algorithms would have to be modified for use in temperate or tropical waters where the fluorescence yield of the phytoplankton may be altered through responses to temperature or macro-nutrient limitations.

(4) The use of algorithms as developed in this paper is intended primarily for use during intensive survey studies where multiple data sets are obtained with profiling instrumentation. To measure chl a concentrations by standard extraction methods for all water column samples in such studies is expensive in regard to personnel time required for the analyses, in addition to the cost of filters and solvents. The accuracy of this first approximation to estimate chl a concentrations is adequate to provide a realistic description of the distribution of chl a with depth in the upper water column, as well as a reliable estimate of the biomass of phytoplankton (expressed either in terms of $\mathrm{chl} a$ or as cellular carbon, assuming a mean carbon/chl a value of approximately 50). However, if one is calculating assimilation numbers in conjunction with primary productivity studies or estimating the ratio of phytoplankton carbon to total particulate organic carbon, it would be advisable to support such calculations with extraction of a limited number of water samples and measurement of chl a by standard methods.

(5) Future studies will have to determine (i) if our algorithms are equally valid when one of the major phylogenetic groups of phytoplankton encountered in Antarctic waters may dominate the phytoplankton assemblage (e.g., in most bloom conditions), in contast to our studies in 1998 when the phytoplankton in our studies described above were predominately a multi-species mixture of diatoms and flagellates and (ii) if daylength or temperature have any significant effect on $F_{\mathrm{N}}$.

Editorial responsibility: Otto Kinne (Editor), Oldendorf/Luhe, Germany
Acknowledgements. This work was supported by NOAA Contract No. 50ABNF600013 to the Antarctic Marine Living Resources Program.

\section{LITERATURE CITED}

Astheimer $H$, Haardt $H$ (1984) Small-scale patchiness of the chlorophyll-fluorescence in the sea: aspects of instrumentation, data processing, and interpretation. Mar Ecol Prog Ser 15:233-245

Falkowski P, Kiefer DA (1985) Chlorophyll a fluorescence in phytoplankton: relationship to photosynthesis and biomass. J Plankton Res 7:715-731

Helbling EW, Villafañe V, Holm-Hansen O (1991) Effect of Fe on productivity and size distribution of Antarctic phytoplankton. Limnol Oceanogr 36:1879-1885

Helbling EW, Villafañe VE, Holm-Hansen O (1995) Variability of phytoplankton distribution and primary production around Elephant Island, Antarctica, during 1990-1993. Polar Biol 15:233-246

Holm-Hansen O, Lorenzen CJ, Holmes RW, Strickland JDH (1965) Fluorometric determination of chlorophyll. J Cons Perm Int Explor Mer 30:3-15

Holm-Hansen O, Riemann B (1978) Chlorophyll a determination: improvements in methodology. Oikos 30:438-447

Holm-Hansen $O$, Hewes CD, Villafañe VE, Helbling EW, Silva N, Amos T (1997) Distribution of phytoplankton and nutrients in relation to different water masses in the area around Elephant Island, Antarctica. Polar Biol 18:145-153

Kiefer DA (1973) Fluorescence properties of natural phytoplankton populations. Mar Biol 22:263-270

Lorenzen CJ (1966) A method for the continuous measurement of in vivo chlorophyll concentration. Deep-Sea Res 13:223-227

Strickland JDH, Parsons TR (1968) A manual of seawater analysis, 2nd edn. Bull Fish Res Board Can 167

Villafañe VE, Helbling EW, Holm-Hansen O (1995) Spatial and temporal variability of phytoplankton biomass and taxonomic composition around Elephant Island, Antarctica, during summers of 1990-1993. Mar Biol 123:677-686

Weber LH, El-Sayed SZ, Hampton I (1986) The variance spectra of phytoplankton, krill and water temperature in the Antarctic Ocean south of Africa. Deep-Sea Res. 33:13271343

Submitted: February 18, 1999; Accepted: October 21, 1999 Proofs received from author(s): March 20, 2000 